\title{
MONITORING OF SERUM LEVELS OF ANGIOGENIN, ENA-78 AND GRO CHEMOKINES IN PATIENTS WITH RENAL CELL CARCINOMA (RCC) IN THE COURSE OF THE TREATMENT
}

\author{
Dagmar Hlávková1, Otakar Kopecký2,5, Šárka Lukešová2,5, Vladimíra Vroblová1, Ctirad Andrýs ${ }^{1}$, Petr Morávek, \\ Miroslav Podhola ${ }^{4}$, Doris Vokurková ${ }^{1}$, Hynek Šafránek ${ }^{3}$
}

Charles University in Prague, Faculty of Medicine in Hradec Králové and University Hospital Hradec Králové, Czech Republic: Department of Clinical Immunology and Allergology ${ }^{1}, 2^{\text {nd }}$ Department of Internal Medicine ${ }^{2}$; Department of Urology ${ }^{3}$; Fingerland's Department of Pathology4; Oncological Department of District Hospital, Náchod ${ }^{5}$

\begin{abstract}
Summary: Tumour progression requires the presence of a rich vascular supply. A number of cytokines, chemokines and proteases participate in the process of tumour angiogenesis. We evaluated serum levels of angiogenin, panGRO (Growth Related Oncogene) (CXCL 1,2,3) and ENA-78 (Epithelial Neutrophil Activating) (CXCL5) in the serum of 32 patients with RCC (renal cell carcinoma) and 14 healthy blood donors by means of a protein array analysis. The patients were divided into three groups according to their disease stages (I+II, III, IV). We discovered significant differences between the blood donors and patients with RCC both in pre-operative and post-operative angiogenin, panGRO and ENA-78 levels. The increase in angiogenic factors lasted in patients even without metastases 2 months after surgery. We found no correlation between the levels of angiogenin and stages I+II, III and IV RCC. Patients with advanced carcinoma (stage III) had pre-operatively higher serum levels of ENA-78 than patients with stages I+II $(p=0,009)$ and IV ( $p<0.001)$. Eight weeks after surgery the patients with stages I+II had significantly higher levels of panGRO than patients with stage IV.
\end{abstract}

Key words: Renal cell carcinoma; Tumour angiogenesis; Multiplex protein array analysis

\section{Introduction}

Neovascularization is important for the growth and development of metastases of solid tumours. It has been proven, that in a number of tumours "microvessel density" correlates with the malignant potential. Malignant cells are exposed during the tumorous expansion to hypoxia, which is the main stimulus for the synthesis of peptides supporting neovascularization. In the case of a physiological situation the dynamic and balanced relationship between proangiogenic and antiangiogenic stimuli exists. However in neoplastic processes the influence of proangiogenic factors prevails (3). Solid tumours do not contain only tumor cells, but also stroma and infiltrating cells. All these cells together create cytokine and chemokine microenvironment, which fundamentally influences a tumour growth and an anti-tumour immune response. More and more evidence of the ambivalent relationship between immune system and tumour cells are appearing. Immune system cells infiltrate the tumour and produce a number of cytokines and chemokines, which participate in the regulation of tumour angiogenesis processes. Soluble factors, as for example IL6 (Interleukin) and CSF-1 (Colony Stimulating Factor), de- rivated by neoplastic cells, participate on the differentiation of the precursor myeloid cells. Tumour-associated macrophages (TAMs) and dendritic cells (DCs) differentiate from circulating monocytes, which enter the tumorous tissue through the effect of chemo-attractive peptides and chemokines (mainly CXCL1-3) $(13,20)$. These cells are the most effective antigen-presenting cells producing proinflammatory cytokines TNF $\alpha$ (Tumor Necrosis Factor), IL-1. TAMs are the most numerous cellular component of the immune system in tumours. Activated TAMs, mainly through IL-2 and IL-12, are able to directly kill tumor cells. But, they also produce a number of cytokines (TGF- $\beta$ (Transforming-Growth Factor), TNF- $\alpha$, IL-8), proteinases, metabolites of arachidonic acid (2), angiogenic and lymfangiogenic growth factors, which can support tumorous growth and the spread of metastases. Through the effect of angiogenic factors produced by tumorous cells, TAMs express VEGF-C (Vascular Endothelial Growth Factor), VEGF-D and VEGFR-3 (VEGF receptor), which participate in lymphangiogenesis and the distribution of metastases through lymphatic vessels. Both TAMs and tumour cells produce IL-10 which effectively blunts a cytotoxic T lymphocyte response to tumour antigens (10). A number of stu- 
dies have proven a significant correlation between TAMs and "tumor vessel density" and their negative influence on the survival of patients. Tumour infiltrating DCs are predominantly immature and their stimulation signals for cytotoxic T lymphocytes are insufficient. The presence of DCs cannot be considered the manifestation of the effective anti-tumour response. DCs can directly produce proangiogenic factors and regulate other components of innate and acquired immune response, which participate in angiogenesis. TAMs and DCs also induce chemotaxis of polymorphonuclear leukocytes (PMNL) through CXCL1, CXCL2, CXCL3, CXCL5, CXCL7, CXCL8 chemokines (26). Due to this stimulation, the increase of adhesive molecules and their ligands occurs on the vascular endothelium and on the PMNL membrane (14). PMNL release large amounts of enzymes, which split the intercellular mass (15). It depends on many factors of tumour microenvironment, whether the anti-tumour immune response or the angiogenic effect prevail.

Tumour growth and its progression is accompanied with the increase in a number of angiogenic factors. There are a number of experimental and clinical observations, which prove the complexity of regulations in angiogenesis. One example is chemokines of the CXC superfamily. These chemokines act both in proangiogenic and angiostatic ways. The difference in effect is given by the sequence of three amino-acids - Glu-Leu-Arg (ELR) at the N terminus (9). $\mathrm{ELR}^{+} \mathrm{CXC}$ chemokines (i.e. CXCL1, CXCL2, CXCL3, CXCL5, CXCL6, CXCL7, CXCL8) show proangiogenic features, while ELR - CXC chemokines (i.e. CXCL4, CXCL9, CXCL10, CXCL11) blunt the proliferation of capillaries (17). In patients with metastatic RCC higher serum levels of CXCL1, CXCL3, CXCL5, CXCL8 were found in comparison with healthy donors (9). ELR ${ }^{+} \mathrm{CXC}$ chemokines significantly increase angiogenesis in various types of tumours $(5,25)$. Growth-related oncogenes- $\alpha, \beta, \gamma$ (GRO- $\alpha, \beta, \gamma$ ) (CXCL1, CXCL2, CXCL3 chemokines) were tested on melanoma cells and they potentiated the proliferation of these cells (8). In the case of patients with a non-small cell lung carcinoma, vascularization and the development of metastases were potentiated by epithelialneurophil-activating peptide 78 (ENA-78) (CXCL5 chemokine) and IL-8 (CXCL8 chemokine) $(11,14)$. On the basis of these findings, we may assume that $\mathrm{ELR}^{+} \mathrm{CXC}$ chemokines are an important factor of malignancy even in other tumours, i.e. renal carcinoma.

The other angiogenic factor, which was evaluated, was angiogenin. Angiogenin is a protein with a molecular weight of $170 \mathrm{kDa}$, it differs from the other members of the superfamily of ribonucleasis by the absence of the 4th disulphide bond between two cysteine residues. Both described $\mathrm{E}$ and $\mathrm{K}$ variants bind to receptors found on endothelial cells and show a proangiogenic effect (19). Angiogenin is detected in a number of organs in the course of embryogenesis (18). Fett (1985) was the first scientist, who proved its influence on the vessel growth of the chicken embryos (4). In healthy individuals the angiogenin concentration in plasma, ranges within $250-360 \mu \mathrm{g} / \mathrm{L}$ (6). Most of the studies which deal with neo-angiogenesis in RCC proved no correlation amongst the disease stage, cellular grading, angiogenin, VEGF and bFGF (basic Fibroblast Growth Factor) levels. No correlation between angiogenin level and survival rate was confirmed either. Significant differences in the serum angiogenin level were described only among healthy blood donors and in patients with metastasing RCC. The angiogenic factors were determined by means of the ELISA method (22).

\section{Material and Methods}

Renal cell carcinoma was diagnosed in 32 patients during the period from October 2005 till September 2006. In all the patients the primary renal tumour was removed. Eight resections and 24 nephrectomies were carried out. The diagnosis of clear cell renal carcinoma was confirmed histologically, and in all the cases the cellular grading was determined according to Fuhrman. Patient sera was obtained by repeated peripheral venous blood collections, which were carried out on the day of surgery, day 7 and 8 weeks post-surgery. None of samples was influenced by an adjuvant therapy. One hour after blood collection each blood sample was centrifuged at $3000 \mathrm{rpm}$ for 10 minutes. Sera was subsequently divided into two parts and stored at a temperature of $-20^{\circ} \mathrm{C}$ till the time of processing. Control sera was obtained from 14 healthy blood donors of similar age. In order to determine the level of angiogenic factors, the protein array method of the RayBiotech Company (USA), RayBio Human Angiogenesis Antibody Array I, was used. This method is based on a membrane covered with spots, where specific antibodies to individual factors under examination are bound. After the application of the sample, the analyzed proteins bind to the appropriate antibodies. In the next step, the mixture of antibodies to measured proteins conjugated with enzyme is applied. The immunocomplexes which came into existence and are fixed in the area of appropriate spots are visualized by a suitable colour reaction. The result is a membrane with visible spots of different intensities. The concentration of an appropriate factor then complies with the intensity of the colouring of a particular spot. The membrane also contains, besides the measured parameters, negative and positive controls. The evaluation was carried out by means of ARES ARay Evaluation System software (Baria, Czech Republic). The resulting concentration of individual proteins was expressed as the relative value of spot colouring in comparison to controls. The statistical evaluation of measured values was carried out by means of the Sigmastat programme.

\section{Results}

The clinical specifications e.g. sex (11 women and 21 men), age (an average age of 65.9 years), disease stage based on TNM classification (10 ${ }^{\text {th }}$ revision, 2002), grade, 
number and localization of metastasis are summarized in Table 1. The results of measurements are shown in Table 2 and the Graphs (Fig. 1a-c, Fig 2a-c, Fig 3a-c).
We discovered a significant increase both in pre-operative (on the day of surgery) and post-operative (on the day 7 and 8 weeks post-surgery) angiogenin, panGRO and

Tab. 1: Clinical characteristics of 32 patients with RCC.

\begin{tabular}{|c|c|c|c|c|c|c|c|c|}
\hline Patient & Sex & Age & Stage & Tumour & Nodes & Metastasis & Grade & $\begin{array}{c}\text { Location, penetration and number } \\
\text { of metastasis lesions }\end{array}$ \\
\hline 01 & $\mathrm{f}$ & 78 & I & T1a & N0 & M0 & II & $\begin{array}{c}\text { none } \\
\end{array}$ \\
\hline 02 & $\mathrm{~m}$ & 74 & $\mathrm{I}$ & T1b & N0 & M0 & II & none \\
\hline 03 & $\mathrm{~m}$ & 80 & I & $\mathrm{T} 1 \mathrm{~b}$ & N0 & M0 & II & none \\
\hline 04 & $\mathrm{~m}$ & 55 & $\mathrm{I}$ & T1b & N0 & M0 & I-II & none \\
\hline 05 & $\mathrm{~m}$ & 55 & I & T1a & N0 & M0 & II & none \\
\hline 06 & $\mathrm{~m}$ & 59 & I & T1b & N0 & M0 & II & none \\
\hline 07 & $\mathrm{~m}$ & 51 & I & T1b & N0 & M0 & III & none \\
\hline 08 & $\mathrm{~m}$ & 78 & $\mathrm{I}$ & $\mathrm{T} 1 \mathrm{~b}$ & N0 & M0 & II & none \\
\hline 09 & $\mathrm{~m}$ & 58 & I & T1a & N0 & M0 & III & none \\
\hline 10 & $\mathrm{f}$ & 72 & I & T1b & N0 & M0 & I-II & none \\
\hline 11 & $\mathrm{f}$ & 46 & $\mathrm{I}$ & T1a & N0 & M0 & $\mathrm{I}$ & none \\
\hline 12 & $\mathrm{~m}$ & 50 & II & $\mathrm{T} 2$ & N0 & M0 & II & none \\
\hline 13 & $\mathrm{~m}$ & 66 & II & $\mathrm{T} 2$ & N0 & M0 & II & none \\
\hline 14 & $\mathrm{~m}$ & 54 & I & T1a & N0 & M0 & III & none \\
\hline 15 & $\mathrm{~m}$ & 78 & $\mathrm{I}$ & T1a & N0 & M0 & II & none \\
\hline 16 & $\mathrm{f}$ & 83 & III & T3a & N0 & M0 & I-II & adrenal \\
\hline 17 & $\mathrm{~m}$ & 66 & III & T3b & N0 & M0 & II & renal vein \\
\hline 18 & $\mathrm{f}$ & 73 & III & T3b & NX & M0 & III & renal vein \\
\hline 19 & $\mathrm{~m}$ & 64 & III & T3b & N0 & M0 & II & renal vein \\
\hline 20 & $\mathrm{~m}$ & 57 & III & T3a & N0 & M0 & II-III & bilteral RCC \\
\hline 21 & $\mathrm{f}$ & 66 & III & T3a & N0 & M0 & II & adrenal \\
\hline 22 & $\mathrm{f}$ & 77 & III & T3a & N0 & M0 & II-III & adrenal \\
\hline 23 & $\mathrm{~m}$ & 75 & III & T3a & N0 & M0 & I-II & adrenal \\
\hline 24 & $\mathrm{~m}$ & 77 & IV & T3a & NX & M1 & III & liver (1) \\
\hline 25 & $\mathrm{~m}$ & 74 & IV & T4 & N0 & M1 & III-IV & skeleton, liver, lung (3) \\
\hline 26 & $\mathrm{f}$ & 70 & IV & T3b & N2 & M0 & III-IV & lymph nodes (1) \\
\hline 27 & $\mathrm{f}$ & 71 & IV & T3a & N0 & M1 & III & liver, peritoneum (2) \\
\hline 28 & $\mathrm{f}$ & 62 & IV & T1b & N0 & M1 & I-II & lymph nodes - mediastinum \\
\hline 29 & $\mathrm{~m}$ & 44 & IV & $\mathrm{T} 3 \mathrm{~b}$ & N0 & M1 & III-IV & liver, lung (2) \\
\hline 30 & $\mathrm{f}$ & 74 & IV & T1b & NX & M1 & III & lung (1) \\
\hline 31 & $\mathrm{~m}$ & 57 & IV & T3b & N0 & M1 & II & skeletal multipath (3) \\
\hline 32 & $\mathrm{~m}$ & 65 & IV & $\mathrm{T} 1 \mathrm{~b}$ & N1 & M1 & III & spine, lung (2) \\
\hline
\end{tabular}

Tab. 2: Comparison of relative levels of chemokines in samples before surgery, 7 days and 8 weeks after surgery.

\begin{tabular}{|c|c|c|c|c|c|c|c|c|c|c|}
\hline & $\begin{array}{c}\text { control } \\
\text { (n 14) }\end{array}$ & stage I+II & stage III & stage IV & $\begin{array}{l}\text { control } \\
\text { vs. I+II }\end{array}$ & $\begin{array}{c}\text { control } \\
\text { vs. III }\end{array}$ & $\begin{array}{l}\text { control } \\
\text { vs. IV }\end{array}$ & $\begin{array}{c}\text { I+II } \\
\text { vs. III }\end{array}$ & $\begin{array}{c}\text { I+II } \\
\text { vs. IV }\end{array}$ & $\begin{array}{c}\text { III } \\
\text { vs. IV }\end{array}$ \\
\hline \multicolumn{11}{|l|}{ Angiogenin } \\
\hline sample 1 & $40,44 \pm 1,67$ & $48,13 \pm 5,12$ & $51,94 \pm 3,39$ & $47,57 \pm 3,73$ & $\mathrm{p}<0,001$ & $\mathrm{p}<0,001$ & $\mathrm{p}=0,003$ & n.s. & n.s. & n.s. \\
\hline sample 2 & $48,50 \pm 6,36$ & $50,25 \pm 4,11$ & $52,14 \pm 4,19$ & $\mathrm{p}=0,002$ & $\mathrm{p}<0,001$ & $\mathrm{p}<0,001$ & n.s. & n.s. & n.s. & \\
\hline sample 3 & $48,34 \pm 5,10$ & $50,67 \pm 2,45$ & $48,90 \pm 4,75$ & $\mathrm{p}<0,001$ & $\mathrm{p}<0,001$ & $\mathrm{p}<0,001$ & n.s. & n.s. & n.s. & \\
\hline \multicolumn{11}{|l|}{ ENA-78 } \\
\hline sample 1 & $3,19 \pm 1,44$ & $9,77 \pm 3,34$ & $14,25 \pm 2,92$ & $6,77 \pm 3,28$ & $\mathrm{p}<0,001$ & $\mathrm{p}<0,001$ & $\mathrm{p}=0,012$ & $\mathrm{p}=0,009$ & n.s. & $\mathrm{p}<0,001$ \\
\hline sample 2 & $11,54 \pm 4,74$ & $15,06 \pm 5,34$ & $10,22 \pm 4,18$ & $\mathrm{p}<0,001$ & $\mathrm{p}<0,001$ & $\mathrm{p}<0,001$ & n.s. & n.s. & n.s. & \\
\hline sample 3 & $12,39 \pm 4,23$ & $12,68 \pm 4,99$ & $8,85 \pm 2,21$ & $\mathrm{p}<0,001$ & $\mathrm{p}<0,001$ & $\mathrm{p}=0,040$ & n.s. & n.s. & n.s. & \\
\hline \multicolumn{11}{|l|}{ GRO } \\
\hline sample 1 & $9,53 \pm 2,87$ & $23,96 \pm 7,41$ & $30,69 \pm 5,44$ & $25,54 \pm 5,59$ & $\mathrm{p}<0,001$ & $\mathrm{p}<0,001$ & $\mathrm{p}<0,001$ & $\mathrm{p}=0,041$ & n.s. & n.s. \\
\hline sample 2 & $31,23 \pm 7,72$ & $31,88 \pm 7,14$ & $26,51 \pm 7,94$ & $\mathrm{p}<0,001$ & $\mathrm{p}<0,001$ & $\mathrm{p}<0,001$ & n.s. & n.s. & n.s. & \\
\hline sample 3 & $31,23 \pm 5,19$ & $28,36 \pm 7,22$ & $21,61 \pm 9,12$ & $\mathrm{p}<0,001$ & $\mathrm{p}<0,001$ & $p=0,004$ & n.s. & $\mathrm{p}=0,018$ & n.s. & \\
\hline
\end{tabular}


ENA-78 levels in all stages of the disease (I+II, III, IV) in comparison with the group of healthy blood donors ( $p$-values in the Table 2).

We found no correlation between the levels of angiogenin and stages I+II, III and IV RCC. Patients with advanced

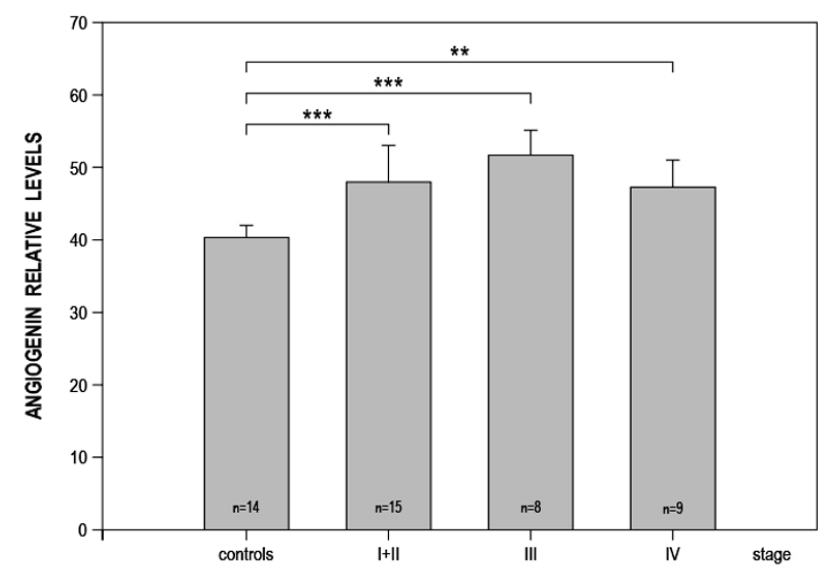

a
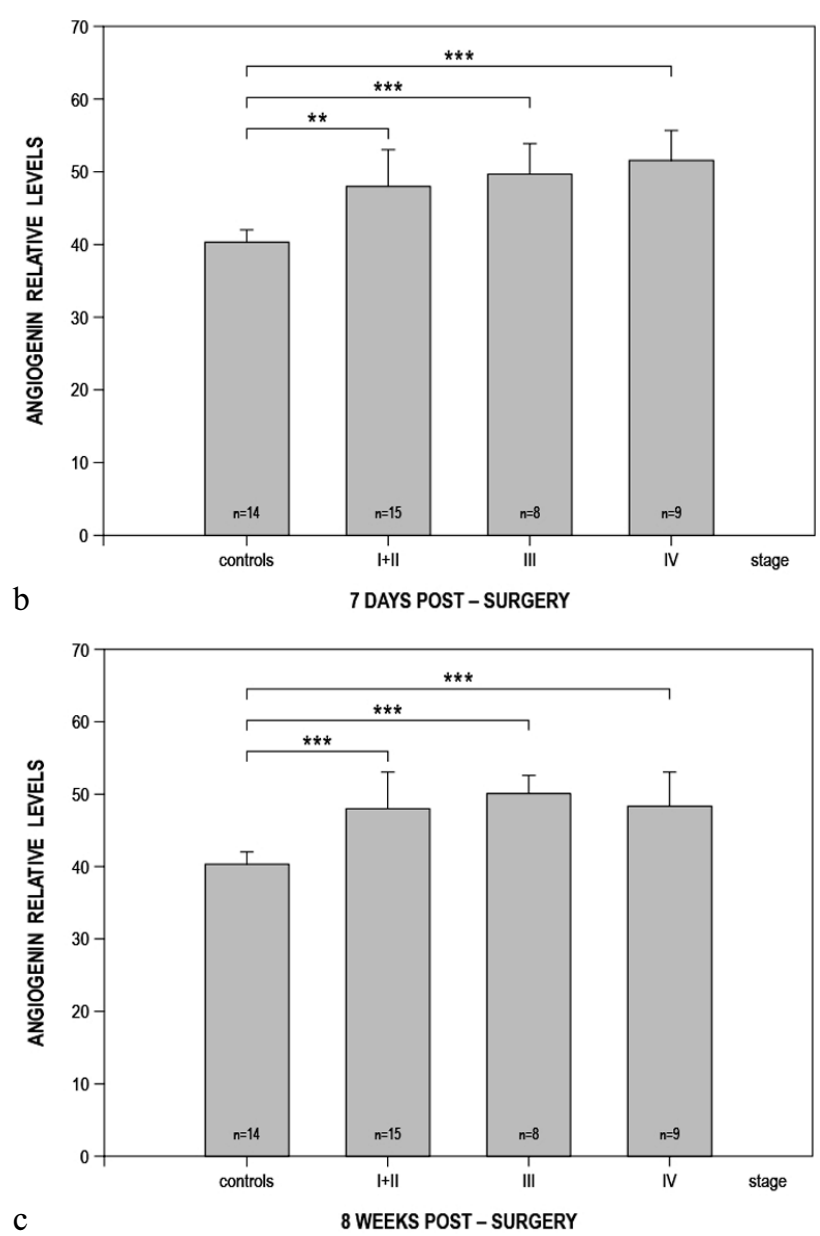

Fig. 1a-c: Serum levels of angiogenin before surgery, 7 days and 8 weeks after surgery. The results are shown as means $\pm \mathrm{SD}$ of relative levels $(* \mathrm{p}<0,05, * * \mathrm{p}<0,01, * * * \mathrm{p}<0,001)$. carcinoma (stage III) had pre-operatively higher serum levels of ENA-78 than patients with stages I+II $(p=0,009)$ and IV $(p<0.001)$. Eight weeks after surgery the patients with stages I+II had significantly higher levels of panGRO than patients with stage IV.
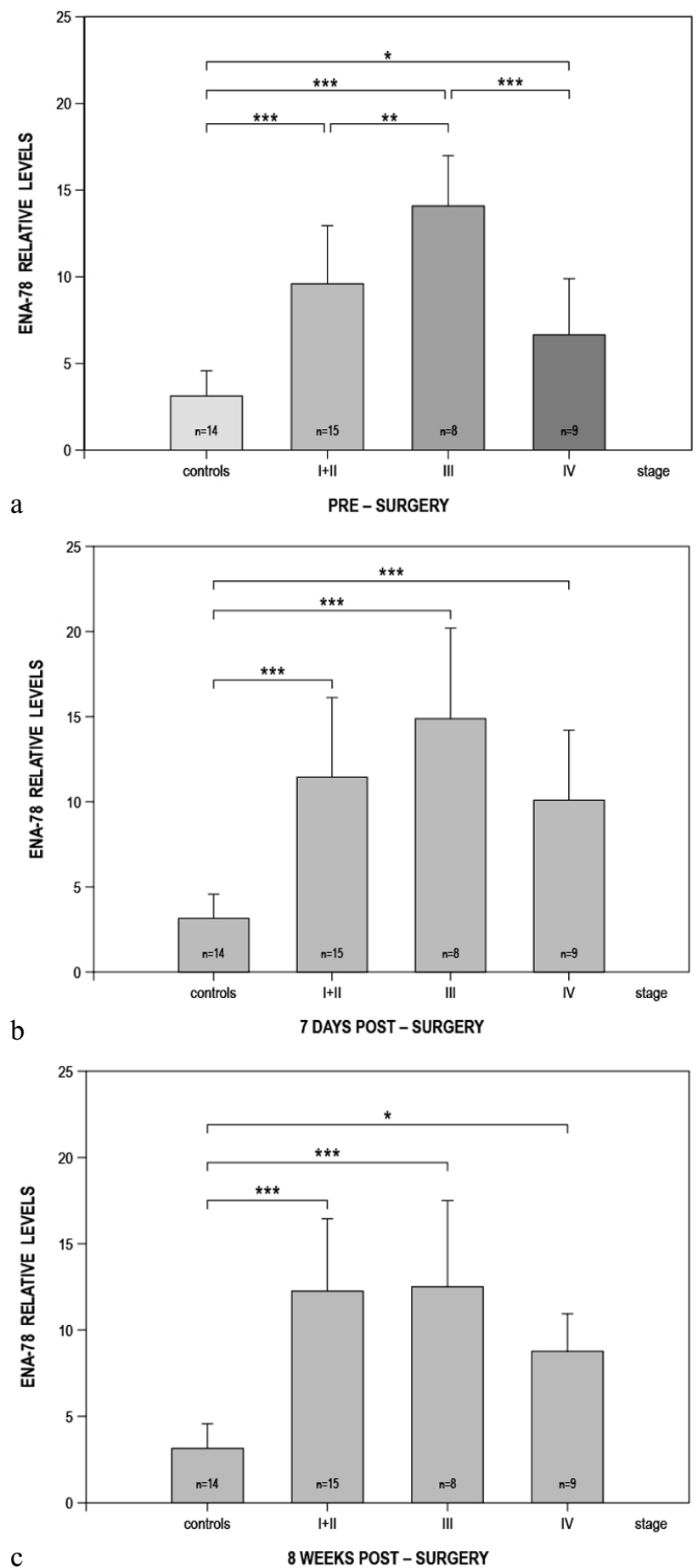

Fig. 2a-c: Serum levels of ENA-78 before surgery, 7 days and 8 weeks after surgery. The results are shown as means \pm SD of relative levels $(* p<0,05, * * p<0,01, * * * p<0,001)$. 


\section{Discussion}

The protein array method, which we used for the analysis, did not allow us to quantify the levels of monitored factors. This method only expresses the ratio of serum con-

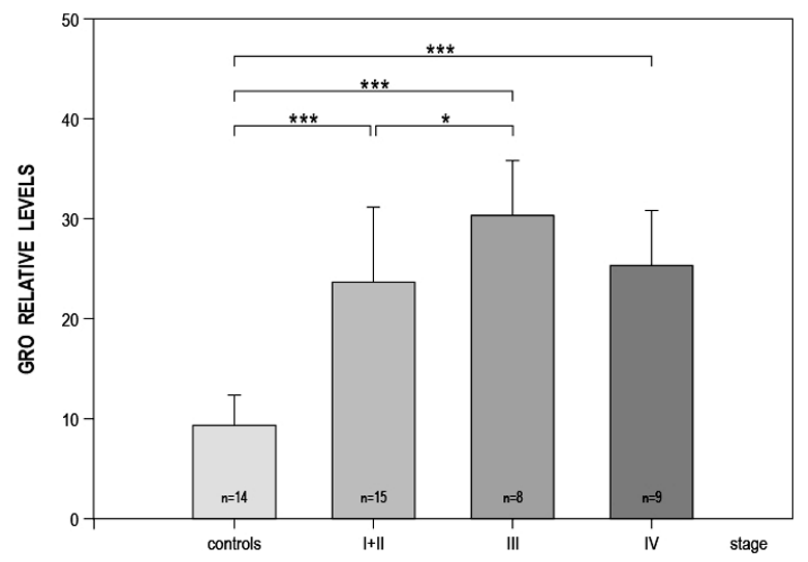

a
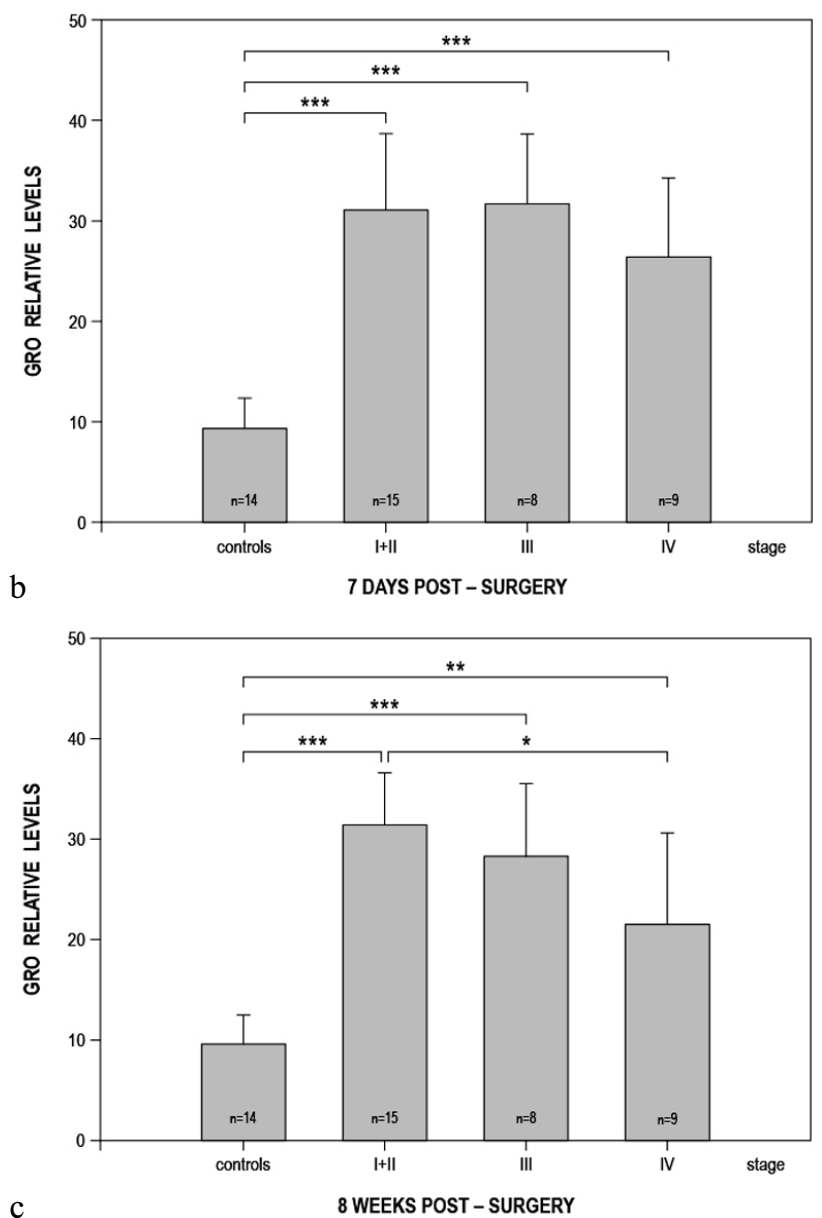

Fig. 3a-c: Serum levels of GRO before surgery, 7 days and 8 weeks after surgery. The results are shown as means \pm SD relative levels $\left(* p<0,05,{ }^{*} p<0,01, * * * p<0,001\right)$. centrations in the samples taken from patients divided into groups based on their disease stage and from healthy blood donors. This method shows good specificity and sensitivity (7, 21). Its big advantage is the possibility to determine a number of parameters in one analytical cycle, but its disadvantage is the detection only in one concentration of the sample under examination. If the analyzed samples contain very low or very high concentrations of measured protein, it is difficult or even impossible to identify them.

In patients with carcinoma (e.g. ovarian, endometrial and renal cancers) a significantly higher level of most of the angiogenic factors in the serum is described.

Similar findings were discovered in our group of patients by means of a multiplex protein array analysis. A significant pre-operative increase in angiogenin of patients in comparison with healthy donors was noted in all stage of RCC. This increase in angiogenin continued two months after the tumour removal, even in patients with stages I and II RCC, without proven metastases. These findings can be explained by the process of postoperative wound healing. By comparing the angiogenin levels before the surgery and one week after the surgery a non-significant difference was seen.

The other following factors were pan GRO (CXCL1-3) and ENA-78 (CXCL-5) chemokines. Similarly, as in the case of angiogenin, we discovered a significant pre-operative increase in panGRO and ENA-78 chemokines both in advanced and metastasing RCC (stages III and IV) and in patients with localized tumours on the kidney (stages I and II). The subsequent slight increase in these chemokines in the samples taken on day 7 after surgery was probably associated with the healing of the post-operative wound. This assumption complies with the studies of $\mathrm{Wu}$ (2003) and Riese (2000) (12, 24).

The long-term increase in angiogenic factors is described also in patients with a burn-healing of the post-operative wound, in patients with the chronic infectious and chronic inflammatory diseases (e.g. diabetes mellitus, rheumatoid arthritis, bronchial asthma, etc. $(1,16,23)$. In our patients, the healing of post-operative wounds was without complications, and none of our patiens suffered from chronic inflammatory disease at the time of surgery.

Laparotomy and following abdominal surgery are accompanied with an increase in IL-1, IL-6, IL-8, G-CFS and MPC-1 in the peritoneal cavity, with or without an insignificant systemic response. The inflammatory post-operative reaction is compartmentalized with the highest cytokine and chemokine concentration at the site of tissue damage (16). These observations explain our findings, why angiogenin, GRO and ENA-78 levels were not significantly increased in the post-operative period and during the healing of post-operative wounds in comparison with preoperative state.

\section{Conclusions}

The study summarizes our experience with the multiparametric analysis of angiogenesis in RCC. The selected 
method allows monitoring the dynamic of changes of serum levels of angiogenin, panGRO and ENA-78 with sufficient sensitivity. However, its prognostic significance has not yet been confirmed. It seems that the serum levels of chemokines in patients with RCC can reflect the advanced stage of disease. Pluripotent ELR+ CXC chemokines play a significant role during the regulation of inflammatory reactions of various etiologies. On top of that, chemokines are quickly degradated already at the site of inflammation, and their serum levels do not reflect the extent of the inflammatory reaction. Only detailed knowledge of the microenvironment, which determines the character of the resulting immune response, can help us interfere in the cellular interactions of the immune system effectively.

\section{Acknowledgements}

This article came into existence thanks to the grant No. NR/8914-4 provided for our research project by the Internal Grant Agency.

\section{References}

1. Avniel S, Arik Z, Maly A, et al. Involvement of the CXC12/CXC4 pathway in the recovery of skin following burns. J Invest Dermatol 2006;16:468-476.

2. Brigati C, Noonan DM, Albini A, Benelli R. Tumors and inflammatory infiltrates: Friends or foes? Clin Exp Metastasis 2002;19:247-258.

3. Coussens LM, Werb Z. Inflammation and Cancer. Nature 2002;420:860-867.

4. Fett JB, Strydom DJ, Lobb RR, et al. Isolation and characterisation of angiogenin, an angiogenic protein from human carcinoma cells. Biochemistry 1985; 24:5480-5486

5. Garkavtsev I, Kozin SV, Chernova O, et al. The candidate tumour suppressor protein ING4 regulates brain tumour growth and angiogenesis. Nature 2004;428: 328-332.

6. Hartmann A, Kunz M, Kostlin S, et al. Hypoxya induced up-regulation of angiogenin in human malignant melanoma. Cancer Res 1999;59:1578-1983.

7. Huang RP, Huang R, Fan Y, Lin Y. Simultaneous detection of multiple cytokines from conditioned media and patient's sera by an antibody-based protein array system. Anal Biochem 2001;294:55-62.

8. Luan J, Shattuck-Brandt R, Haghnegahdar H, et al. Mechanism and biological significance of constitutive expression of MGSA/GRO chemokines in malignant melanoma tumor progression. J Leukoc Biol 1997;62:588-97.
9. Mestas J, Burdick MD, Reckamp K, Pantuck A, Figlin RA, Strieter RM. The role of CXC2/CXCR2 ligand biological axis in renal cell carcinoma. J Immunol 2005; $175: 5351-5357$

10. Mu W, Ouyang X, Agarwal A, et al. IL-10 Suppresses chemokines, inflammation, and fibrosis in a model of chronic renal disease. J Am Soc Nephrol 2005;16: $3651-3660$

11. Murdoch C, Finn A. Chemokine receptors and their role in inflammation and infectious diseases. Blood 2000;95:3032-3043.

12. Riese J, Schoolmann S, Beyer A, Denzel C, Hohenberger W, Haupt W. Production of IL-6 and MCP-1 by the human peritoneum in vivo during major abdominal surgery. Shock 2000;14(2):91-4.

13. Schoppmann SF, Birner P, Stöckl J, et al. Tumor-Associated Macrophages Express Lymphatic Endothelial Growth Factors and Are Related to Peritumora Lymphangiogenesis. Am J Pathol 2002;161:947-956.

14. Schröder A, von der Ohe M, Kolling U, et al. Polymorphonuclear leucocytes selectively produce anti-inflammatory interleukin-1 receptor antagonist and chemokines, but fail to produce pro-inflammatory mediators. Immunol 2006;119: 317-327.

15. Scimone ML, Lutzky VP, Zittermann SI, et al. Migration of polymorphonuclear leucocytes is influenced by dendritic cells. Immunol 2005;114:375-385.

16. Sido B, Teklote JR, Hartel M, Friess H, Buchler MW. Inflammatory response after abdominal surgery. Best Pract Res Clin Anaesthesiol 2004;18:439-459.

17. Smith DF, Galkina E, Ley K, Huo Y. GRO family chemokines are specialized for monocyte arrest from flow. AJP-Heart Circ Physiol 2005;76:1976-1984.

18. Strydom DJ. The angiogenin. Cell Mol Life Sci 1998;54:811-824.

19. Tello-Montoliu A, Patel JV, Lip GY. Angiogenin: a review of the pathophysiology and potential clinical applications. J Thromb Haemost 2006;4:1864-1874.

20. Tsung K, Dolan JP, Tsung YL, Norton JA. Macrophages as effector cells in interleukin 12-induced T cell-dependent tumor rejection. Cancer Res 2002;62: 5069-75.

21. Wang CC, Huang RP, Sommer M, et al. Array-based multiplexed screening and quantitation of human cytokines and chemokines. J Proteome Res 2002;4: $337-43$

22. Wechsel HW, Bichler KH, Feil G, Loeser W, Lahme S, Petri E. Renal cell carcinoma: relevance of angiogenetic factors. Anticancer Res 1999;19:1537-1540.

23. Wetzler Ch, Kämpfer H, Stallmeyer B, Pfeilschifter J, Frank S. Large and sustained induction of chemokines during impaired wound healing in the genetically diabetic mouse: Prolonged persistence of neutrophils and macrophages during the late phase of repair. J Invest Dermatol 2000;115:245-253

24. Wu FP, Sietses C, von Blomberg BM, Meijer S, Bonjer HJ, Cuesta MA. Systemic and peritoneal angiogenic response after laparoscopic or conventional colon resection in cancer patients: a prospective, randomized trial. Dis Colon Rectum 2004;47(10):1670-4.

25. Yatsunami J, Tsuruta N, Ogata K, et al. Interleukin-8 participates in angiogenesis in non-small cell, but not small cell carcinoma of the lung. Cancer Lett 1997; 120:101-108

26. Zijlstra A, Seandel M, Kupriyanova TA, et al. Proangiogenic role of neutrophillike inflammatory heterophils during neovascularization induced by growth factors and human tumor cells. Blood 2006;107:317-327.

Submitted December 2007. Accepted June 2008

\section{Corresponding author:}

MUDr. Dagmar Hlávková, University Hospital Hradec Králové, Department of Clinical Imunology and Alergology, Sokolská 581, 50005 Hradec Králové, Czech Republic; e-mail: hlavkova1@seznam.cz 